\title{
Seasonal and Local Time Variations of $E$-Region Field-Aligned Irregularities Observed with 30.8-MHz Radar at Kototabang, Indonesia
}

\author{
Y. Otsuka \\ Solar-Terrestrial Environment Laboratory, Nagoya University, Nagoya, Japan \\ Correspondence should be addressed to Y. Otsuka, otsuka@stelab.nagoya-u.ac.jp \\ Received 1 December 2011; Accepted 15 March 2012 \\ Academic Editor: R. Dabas
}

Copyright (C) 2012 Y. Otsuka. This is an open access article distributed under the Creative Commons Attribution License, which permits unrestricted use, distribution, and reproduction in any medium, provided the original work is properly cited.

\begin{abstract}
A VHF backscatter radar with operating frequency $30.8 \mathrm{MHz}$ has been operated at Kototabang $\left(0.20^{\circ} \mathrm{S}, 100.32^{\circ} \mathrm{E}\right.$; dip latitude $10.36^{\circ} \mathrm{S}$ ), Indonesia, since February 2006. We analyzed E-region field-aligned irregularities (FAIs) observed by this radar through a year of 2007 and found that the E-region FAI observed at Kototabang can be classified into two groups. One is "descending FAI". Altitude of the FAI echo region descends with time from $102 \mathrm{~km}$ to $88 \mathrm{~km}$ altitude during $0700-1000$ and $1900-0000$ LT in June solstice season. The other is "low-altitude FAI", which is observed in an altitude range from 88 to $94 \mathrm{~km}$ mainly during nighttime. The observed Doppler velocity show distinct local time and altitude dependence. The seasonally averaged zonal velocity above (below) approximately $94 \mathrm{~km}$ altitude is westward (eastward) during daytime and eastward (westward) during nighttime. Meridional/vertical velocity perpendicular to the geomagnetic fields is upward during daytime and downward during nighttime. The direction of the FAI velocity above approximately $94 \mathrm{~km}$ altitude is consistent with that of the background $\mathbf{E} \times \mathbf{B}$ plasma drifts reported previously.
\end{abstract}

\section{Introduction}

VHF, UHF, and L-band radars are used for observations of the Bragg scatter echo from field-aligned irregularities (FAIs) with a spatial scale of one half the radar wavelength. Regarding the E-region FAIs at mid-latitudes, using a powerful radar, middle and upper atmosphere (MU) radar at Shigaraki, Japan, Yamamoto et al. [1] have discovered two types of the E-region FAI echoes: quasiperiodic (QP) and continuous echoes. The QP echoes appearing intermittently at altitudes of sporadic $E(E s)$ layer (above $100 \mathrm{~km}$ ) with periods of 5-20 min. Morphological features of the QP echoes have been reported by Yamamoto et al. [2]. Occurrence rate of the QP echoes shows distinct seasonal variation with a maximum in summer and rises abruptly after the local sunset and decreases after midnight. Numerous experimental and theoretical studies have been made to disclose the mechanisms generating the QP echoes (e.g.,[3-7]). On the other hand, the continuous FAI echoes appear continuously in time at low-altitude of the E-region (90-100 km), mainly around sunrise and occasionally at postmidnight [8].

However, studies of the E-region FAIs at low latitudes are limited compared to those at the mid-latitude regions. Using the Piura VHF radar in Peru $\left(5.2^{\circ} \mathrm{S}, 80.6^{\circ} \mathrm{W}\right.$; dip latitude $\left.7^{\circ} \mathrm{N}\right)$ and the Gadanki MST radar in India $\left(13.5^{\circ} \mathrm{N}, 79.2^{\circ} \mathrm{E}\right.$; dip latitude $6.3^{\circ} \mathrm{N}$ ), Chau et al. [9] and Patra et al. [10] have reported statistical characteristics of the E-region FAIs, respectively. Using the Gadanki radar, Patra et al. [11] and Pan and Rao [12] have observed QP echoes at altitudes lower than those of the usual QP echoes.

The Equatorial Atmosphere Radar (EAR) was installed at Kototabang $\left(0.20^{\circ} \mathrm{S}, 100.32^{\circ} \mathrm{E}\right.$; dip latitude $\left.10.36^{\circ} \mathrm{S}\right)$ in West Sumatra, Indonesia, on 2001 March [13]. E-region FAI observations have been performed using the EAR and Fukao et al. [13] have shown that the $E$ region echoes above $100 \mathrm{~km}$ are quite similar to those at other low-latitude 
and mid-latitude locations. Patra et al. [14] have performed simultaneous wind observations made using a meteor radar installed at the EAR site and compared the meteor with the FAI Doppler velocities. Their results show that the low-altitude FAI velocities are controlled mainly by neutral winds.

As described above, the EAR is a powerful tool to observe E-region FAIs at Kototabnag, Indonesia. However, the EAR is usually operated in a mode of troposphere and stratosphere measurements, and the ionospheric FAI measurements are made only approximately 4 weeks a year, on average although the routine measurements have started since July 2010. Consequently, a climatological study of the $E$ region FAIs has not been made yet. To make continuous observations of FAIs over Indonesia, a VHF radar with an operating frequency of $30.8 \mathrm{MHz}$ has been installed at the EAR site. The present paper reports seasonal and local time variations of FAIs observed with the 30.8-MHz radar at Kototabang, Indonesia, which is located at magnetically low-latitude.

\section{Observations}

A VHF backscatter radar with an operating frequency of $30.8 \mathrm{MHz}$ was installed at Kototabang, Indonesia, on February 2006. Specification of the radar system is shown in Table 1. Peak and average transmitting powers are $20 \mathrm{~kW}$ and $1.5 \mathrm{~kW}$, respectively. The antenna is composed of a linear array of 18 three-element Yagi antennas and aligned in zonal direction with a total length of $117 \mathrm{~m}$. The VHF radar has a capability to steer the radar beam to 9 directions between $\pm 54^{\circ}$ in azimuth around geographic south $\left(126^{\circ}-\right.$ $234^{\circ}$ ). Zenith angle of all the radar beams is set at $20^{\circ}$. Halfpower full-beam widths in azimuth and zenith directions are $12^{\circ}$ and $40^{\circ}$, respectively. The perpendicularity between the radar beam and geomagnetic field line can be achieved within the half-power full-beam width.

The VHF radar was operated routinely in a mode which consisted of $E$ and $F$ region FAI measurements. For the $E$ region FAI measurements through a year of 2007, five beams with azimuth of $125.8^{\circ}, 153.0^{\circ}, 180.0^{\circ}, 207.0^{\circ}$, and $234.2^{\circ}$ were steered to reveal spatial and temporal variations of the FAI echoes. This arrangement covered approximately $90 \mathrm{~km}$ in zonal direction at $100 \mathrm{~km}$ altitude. This coverage is almost same as the EAR multibeam measurements conducted by Patra et al. [14]. The range and time resolutions of the VHF radar measurement were $1.2 \mathrm{~km}$ and about 56 seconds, respectively. Details of the observational mode are listed in Table 2.

In this study, the altitude of the target from which the radar echo comes is defined as the altitude at which center of the radar beam is perpendicular to the geomagnetic field. It is important to note that the radar beam of this radar is rather broad in both azimuth and elevation so that the altitude shown in this study may be inaccurate. Furthermore, since the operating frequency of $30.8 \mathrm{MHz}$ is relatively low compared to other coherent radar for the FAI measurements, the altitude of the radar echo may be underestimated due to the refraction of the radio wave.
TABLE 1: Specifications of the VHF radar at Kototabang.

\begin{tabular}{|c|c|}
\hline Location & $0.20^{\circ} \mathrm{S}, 100.32^{\circ} \mathrm{E}$ \\
\hline Dip latitude & $10.36^{\circ} \mathrm{S}$ \\
\hline Operating frequency & $30.8 \mathrm{MHz}$ \\
\hline Antenna & $\begin{array}{l}\text { Linear array of } 18 \text { three-element Yagi } \\
\text { antennas }\end{array}$ \\
\hline Gain & $22 \mathrm{dBi}$ \\
\hline Beam width & $\begin{array}{l}12^{\circ} \text { in azimuth (half-power full-width) } \\
40^{\circ} \text { in zenith (half-power full-width) }\end{array}$ \\
\hline Beam steering & $\begin{array}{l}\text { Active phase control Azimuthal beam } \\
\text { directions between }+54^{\circ} \text { and }-54^{\circ} \text { at } \\
13^{\circ} \text { step }\end{array}$ \\
\hline Transmitter & Solid-state pulse transmitter \\
\hline Peak power & $20 \mathrm{~kW}$ \\
\hline Average power & $1.5 \mathrm{~kW}$ \\
\hline Pulse width & $1-200 \mu \mathrm{s}$ \\
\hline Subpulse width & $1,2,4,8,16 \mu \mathrm{s}$ \\
\hline Receiver & Single coherent receiver \\
\hline A/D converter & 16 bit \\
\hline
\end{tabular}

TABLE 2: Observational mode for E-region FAI.

\begin{tabular}{|c|c|}
\hline Parameter & Value \\
\hline Azimuth of beams & $\begin{array}{l}234.2^{\circ}, 207.0^{\circ}, 180.0^{\circ}, 153.0^{\circ}, 125.8^{\circ} \\
\text { from due north }\end{array}$ \\
\hline Interpulse period & $1.6 \mathrm{~ms}$ \\
\hline Transmitted pulse & $64 \mu \mathrm{s}(8 \mu \mathrm{s} \times 8$-bit complementary $)$ \\
\hline $\begin{array}{l}\text { Number of coherent } \\
\text { integration }\end{array}$ & 2 \\
\hline Number of FFT points & 256 \\
\hline $\begin{array}{l}\text { Number of spectral } \\
\text { average }\end{array}$ & 3 \\
\hline Range resolution & $1.2 \mathrm{~km}$ \\
\hline Sampling intervals & $1.2 \mathrm{~km}$ \\
\hline Range & $90.0-141.6 \mathrm{~km}$ \\
\hline Time resolution & 56 seconds. \\
\hline
\end{tabular}

\section{Results}

Figure 1 shows range-time-SNR plots of the E-region FAI echoes observed in the five radar beams on July 29, 2007. Color scale represents signal-to-noise ratio (SNR) of the FAI echoes. The vertical scale at the right of each figure shows the altitude at which the radar beam is perpendicular to the geomagnetic field. The echo region of the $E$ region FAI descended approximately from $100 \mathrm{~km}$ to $90 \mathrm{~km}$ altitude between 0700 and 1100 LT and then disappeared. Around the sunset (1800 LT), the FAI appeared again at an altitude of approximately $100 \mathrm{~km}$ and descend with time to approximately $90 \mathrm{~km}$ until $2300 \mathrm{LT}$, indicating semidiurnal variation of the descending FAIs. Between 0000 and 0600 LT, the other descending FAI was observed. Zenith angle of the five radar beams ranges between $21^{\circ}$ and $33^{\circ}$, assuming that 
the FAI echo comes from the point where the radar beam is perpendicular to the geomagnetic field. The displacement of the FAI echo toward the radar is, in general, a combination of the horizontal displacement toward the radar and downward displacement. However, for the current event as shown in Figure 1, altitude of the FAI echo region is almost identical among the five radar beams. This feature was seen in most $E$-region FAI events and indicates that the FAI regions move in the vertical direction rather than the horizontal direction. In the current study, we interpret the FAI displacement as the vertical displacement of the FAI region.

Figure 2 shows the Doppler velocity in the five radar beams on July 29, 2007. In this study, the Doppler velocity was obtained from the first moment of the FAI echo spectrum. We adopt the data with SNR larger than $0 \mathrm{~dB}$ in order to exclude noisy data. From the figure, we find that the Doppler velocity varies with local time and altitude. The Doppler velocity in an upper part of the E-region FAI echoes (approximately above $94 \mathrm{~km}$ altitude) between 0700 and 1200 LT is negative (away from the radar) on westward beam and positive (toward the radar) on eastward beam, indicating westward velocity of the FAI. On the other hand, between 0000 and $0600 \mathrm{LT}$, the Doppler velocity in an upper part of the E-region FAI echoes is toward the radar on westward beam and away from the radar on eastward beam, indicating eastward velocity.

Therefore, the zonal velocity was westward during daytime and eastward during nighttime. The Doppler velocity in the lower $E$ region (approx. below $94 \mathrm{~km}$ altitude) between 1800 and $2300 \mathrm{LT}$ is toward the radar on all of the five beams, indicating northward/downward velocity perpendicular to the magnetic fields.

By analyzing the E-region FAI data obtained with the VHF radar at Kototabang through a year of 2007, we investigate seasonal and local time variations of the FAI echo occurrence rate. The one-year interval was divided into three seasons, namely, June solstice season (MayAugust), December solstice season (November-February), and equinox (March, April, September, and October). Figure 3 shows local time and altitude variations of FAI occurrence rate in each hourly and altitude bin. We defined the occurrence rate as the ratio of the time period duration of the FAI occurrence to the hourly observation intervals for each altitude bin. The altitude bin corresponds to the sampling interval of $1.2 \mathrm{~km}$ in range. From Figure 3, we find two types of the E-region FAI. One is "descending FAI", which can be seen most clearly in June solstice season. Altitude of the FAI echo region descends with time from $102 \mathrm{~km}$ to $88 \mathrm{~km}$ altitude between 0700 and $1000 \mathrm{LT}$. In winter, the descending FAI is less pronounced. Another descending FAIs can be seen between 1900 and 0000 LT in the June solstice season, indicating semidiurnal variation of the FAI appearance. The other type of the FAI is "low-altitude FAI." The FAI echo was observed at around 88-94 km mainly during nighttime, and the altitude of the echo region is mostly constant with time through a night.

Figure 4 shows averaged Doppler velocities of the $E$ region FAIs observed in the southward beam with the VHF radar at Kototabang in 2007 for different seasons. All of
VHF radar at Kototabang: 20070729

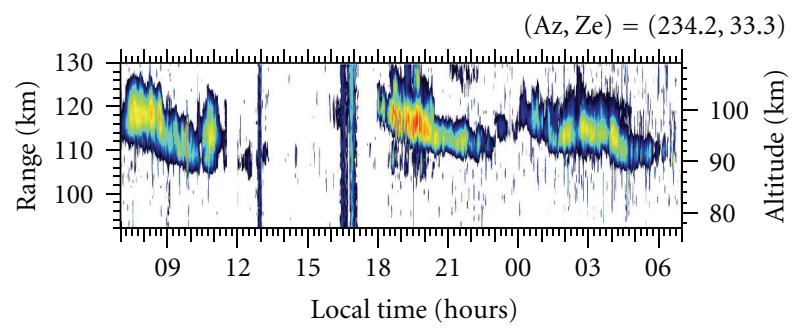

$(\mathrm{Az}, \mathrm{Ze})=(207,23.1)$

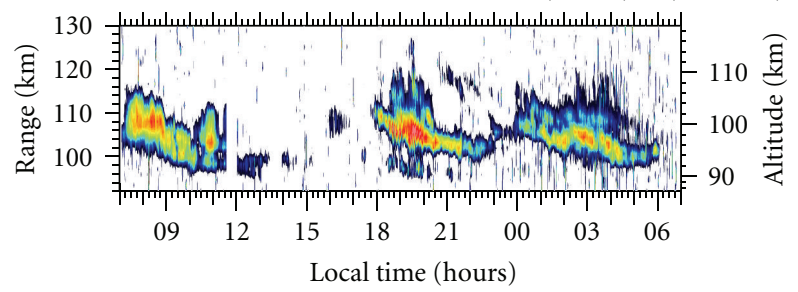

$(\mathrm{Az}, \mathrm{Ze})=(180,20.7)$

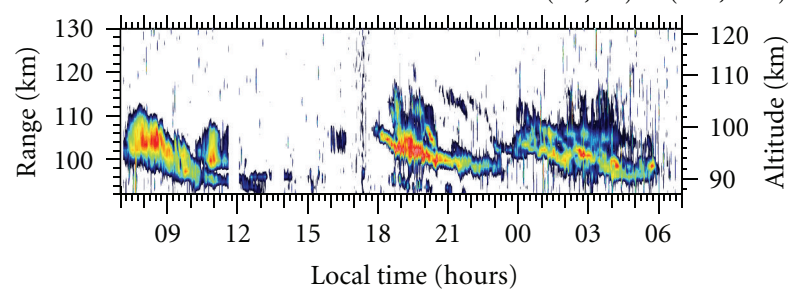

$(\mathrm{Az}, \mathrm{Ze})=(153,22.9)$

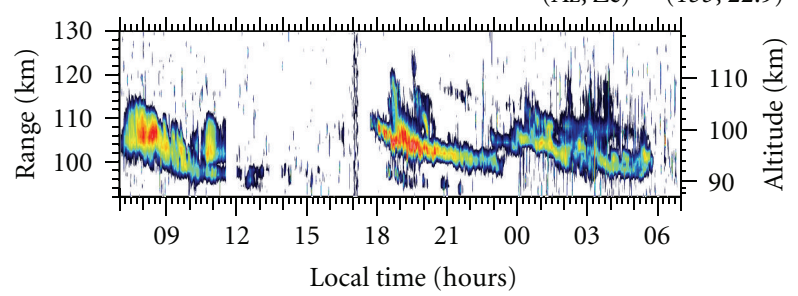

$(\mathrm{Az}, \mathrm{Ze})=(125.8,32.6)$

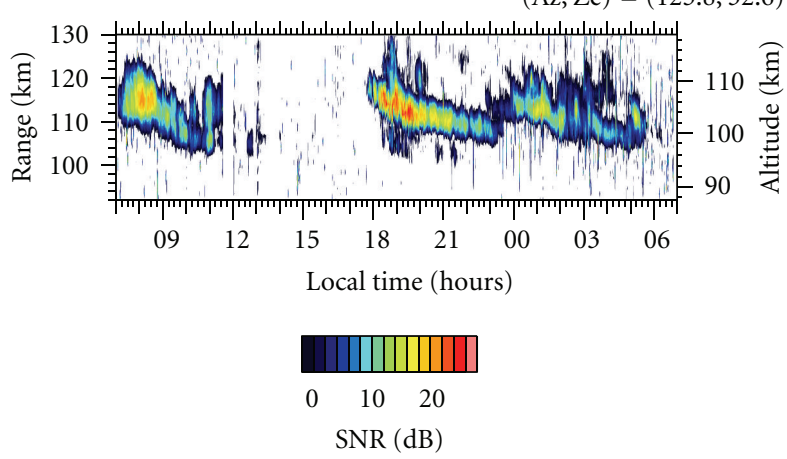

FIgURE 1: Range-time-SNR plot of the E-region Field-Aligned Irregularity (FAI) observed on beams with azimuth $125.8^{\circ}, 153.0^{\circ}$, $180.0^{\circ}, 207.0^{\circ}$ and $234.2^{\circ}$ (top to bottom panels) with the $30.8 \mathrm{MHz}$ radar at Kototabang, Indonesia on July 29, 2007. Left vertical axis shows the range from the radar and the right axis shows the altitude at which the radar beam is perpendicular to the geomagnetic field.

the FAI observed at Kototabang in 2007 were classified into each bin of an hour and a sampling interval in range $(1.2 \mathrm{~km})$, and the data within each bin are averaged to obtain averaged Doppler velocity. The results show that direction 
of the Doppler velocity is different between daytime and nighttime; the velocity is southward/upward during daytime and northward/downward during nighttime.

Zonal velocity of the FAI is obtained from combining the Doppler velocities on eastward and westward beams. Figure 5 shows local time variation of the averaged zonal velocity (positive eastward). The velocity depends on not only local time but also altitude. In the lower (higher) altitudes of the FAI echo regions, the velocity is eastward (westward) during daytime and westward (eastward) during nighttime.

\section{Discussion and Conclusions}

Based on the seasonal and local time variations of the FAI echo occurrence rate, the E-region FAI observed at Kototabang can be classified into two groups. One is "descending FAI." Altitude of the FAI echo region descends with time from $102 \mathrm{~km}$ to $88 \mathrm{~km}$ altitude during 0700 1000 and 1900-0000 LT. The descending FAIs are frequently observed in the June solstice season compared with other seasons. The other is "low-altitude FAI." The FAI echo appears around $88-94 \mathrm{~km}$ and the altitude of the echo region is mostly constant with time through a night. The altitude of the low-altitude FAI is consistent with that of the continuous FAIs observed at Shigaraki, Japan (e.g., [8]). However, the continuous FAIs in Japan occur after midnight and continue until the morning, whereas the low-altitude FAIs at Kototabang appear after sunset and continue through a night with maximum occurrence rate between sunset and midnight. This difference could be attributed to latitudinal dependence of the E-region FAIs.

From the spectral characteristics, the FAIs observed by the VHF radar at Kototabang are considered to be type-2 echo. The Doppler velocity $\left(V_{d}\right)$ observed by the radar in the meridional beam is given by (e.g., [15])

$$
V_{d}=\frac{1}{1+\psi} \frac{E_{E-W}}{B}+\frac{\psi}{1+\psi} U_{N-S} \sin \theta,
$$

where $E_{E-W}$ is zonal component of the electric field, $B$ is the magnetic field, $U_{N-S}$ is meridional component of the neutral wind, $\theta$ is zenith angle of the radar beam. $\psi=v_{e} \nu_{i} / \omega_{e} \omega_{i}$, where $\nu_{e}\left(\nu_{i}\right)$ is the electron (ion) collision frequency and $\omega_{e}\left(\omega_{i}\right)$ is the electron (ion) cyclotron frequency. Here, the contribution of vertical neutral winds is neglected. $\psi$ decreases with altitude because collision frequency, which proportional to the neutral density decreases with altitude. At an altitude around $95 \mathrm{~km}, \psi$ is equal to unity, then $1 /(1+$ $\psi)=\psi /(1+\psi)[16]$. Therefore, at higher altitudes above $95 \mathrm{~km}(\psi \ll 1)$, the Doppler velocities are dominated by the $\mathbf{E} \times \mathbf{B}$ drift, whereas at lower altitudes $(\psi \gg 1)$, it is dominated by the meridional neutral wind.

As shown in Figures 4 and 5, the velocities of the observed FAIs above approximately $94 \mathrm{~km}$ altitude is westward and southward (upward) during daytime, and eastward and northward (downward) during nighttime. The direction of the FAI velocity is consistent with the $\mathbf{E} \times \mathbf{B}$ plasma drift measured by the Jicamarca incoherent scatter radar [17].
VHF radar at Kototabang: 20070729

$(\mathrm{Az}, \mathrm{Ze})=(234.2,33.3)$

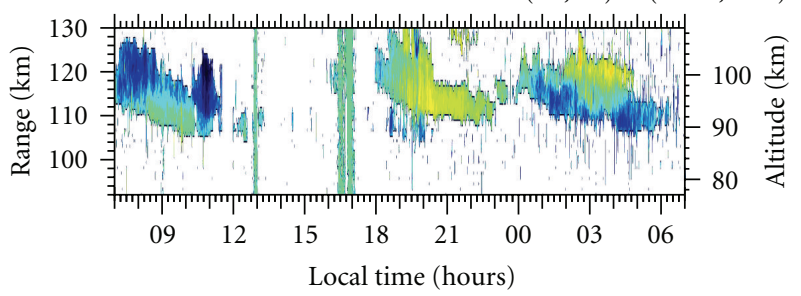

$(\mathrm{Az}, \mathrm{Ze})=(207,23.1)$

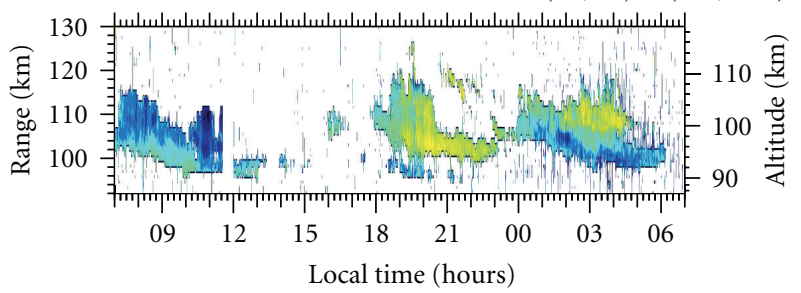

$(\mathrm{Az}, \mathrm{Ze})=(180,20.7)$

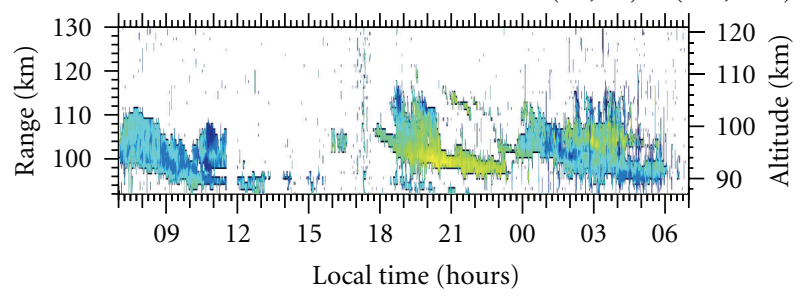

$(\mathrm{Az}, \mathrm{Ze})=(153,22.9)$

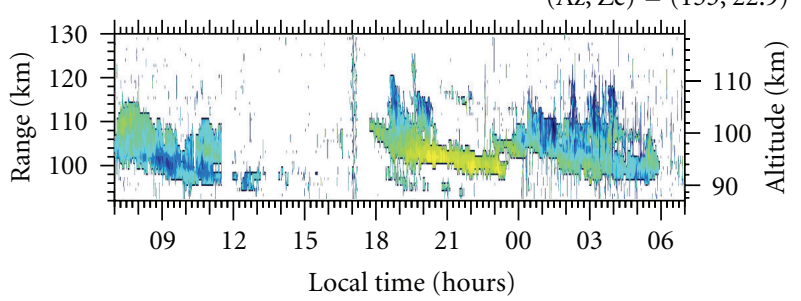

$(\mathrm{Az}, \mathrm{Ze})=(125.8,32.6)$
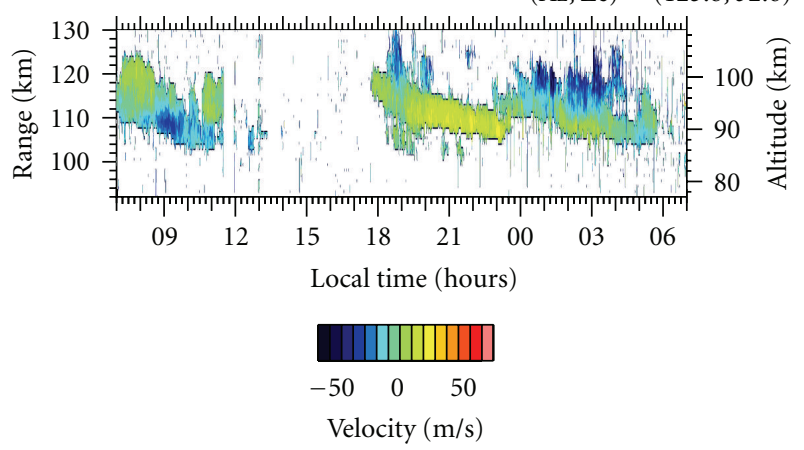

FIGURE 2: Same as Figure 1, but for line-of-sight Doppler velocities of the E-region FAIs (positive toward the radar).

This feature is different from the mid-latitude FAIs observed by the MU radar in Japan $[1,2]$. The mid-latitude FAIs show westward velocities. This is probably because the velocity of the mid-latitude FAIs corresponds to the $\mathbf{E} \times \mathbf{B}$ drift caused by the polarization electric fields through the $E$ and $F$ region electrodynamical coupling processes associated with medium-scale traveling ionospheric disturbances (MSTIDs) 

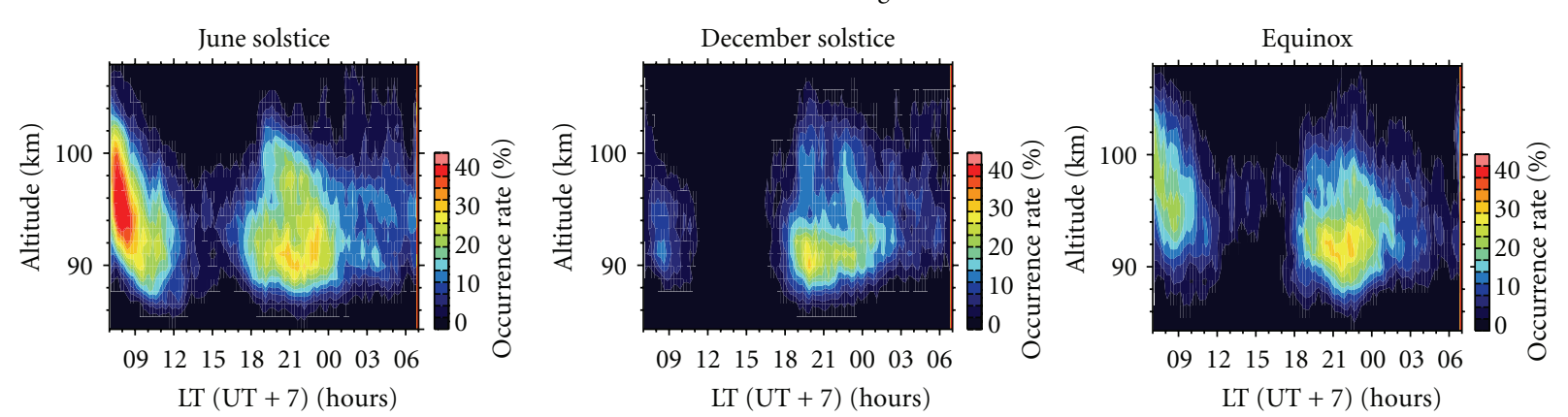

FIgURe 3: Local time and altitude variations of FAI occurrence rate at Kototabang, Indonesia, for (a) June solstice, (b) December solstice, and (c) equinox seasons in 2007.

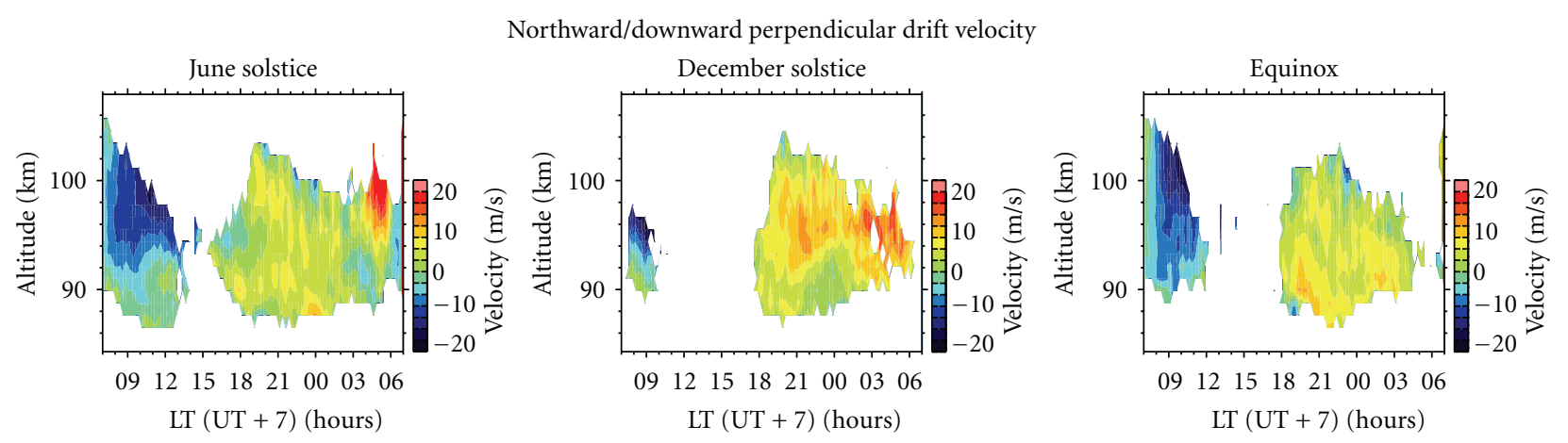

FIgURE 4: Local time and altitude variations of averaged Doppler velocity of the E-region FAIs in the southward/downward perpendicular direction to the magnetic fields (a) June solstice, (b) December solstice, and (c) equinox seasons in 2007.

in the $F$ region $[18,19]$. At mid-latitudes, both $E$-region FAIs and MSTIDs have band-like structures elongated from NW to SE in the northern hemisphere (from NE to SW in the southern hemisphere). At Kototabang, occurrence rate of such mid-latitude MSTIDs is low [20]. Therefore, the morphological features of the low-latitude FAIs are different from those at mid-latitudes although the underlying basic plasma instability processes are similar.

In the lower altitude of the FAI echo regions (below $94 \mathrm{~km}$ altitude), the Doppler velocity is westward during nighttime. This is probably due to westward neutral wind in consistence with the work of Patra et al. [14]. Altitude gradient of the plasma density can be considered to be upward at this altitude range $(88-94 \mathrm{~km}$ altitude). This region is stable for the gradient drift instability. However, if neutral wind is eastward, it can make this region unstable via the gradient drift instability. Other processes may operate as the generation mechanism of the FAIs in the low-altitude $E$ region. One of possible mechanisms is the Kelvin-Helmholtz instability [21]. This instability could generate turbulence of the neutral atmosphere. Since the ion-neutral collision frequency is high in the lower E-region, the plasma moves at the almost same velocity as the neutral particles, so that the ionospheric irregularities are produced. When Richardson number is less than 0.25 , this process operates and generates structures similar to the Kelvin-Helmholtz billows. In terms of this process, the mid-latitude quasi-periodic (QP) echo has been explained. On the other hand, at low latitude, using the Gadanki radar, Sripathi et al. [22] have observed the daytime QP echo with periods in the range 1-3 minutes and suggested that the Kelvin-Helmholtz instability seems to be the most likely mechanism to explain the daytime QP echoes.

The Doppler velocity of the low-altitude FAIs shows semidiurnal signature; the westward velocity becomes large at sunset and postmidnight, and weak around 2200 LT. This semidiurnal signature is most clearly seen in June solstice and equinox. Chau et al. [9], who have investigated the Eregion FAI observed with the VHF radar at Piura, report that the Doppler velocity of the FAI shows semidiurnal pattern, particularly between April and July. Furthermore, the current study shows that the descending FAI echoes appear at 07001100 and 1900-2400 LT, indicating semidiurnal variation. The descending rate of the echo region is approximately 3 $4 \mathrm{~km} / \mathrm{h}$, which is consistent with downward phase velocity of the semidiurnal tide and sporadic E (Es) layer [23]. Es layer could be formed by the convergence of ions due to the vertical shear in zonal wind which is eastward below the Es layer and westward above the Es layer [24]. The descending FAIs observed at Kototabang could be accompanied by the Es layer.

At mid-latitudes, the E-region FAIs do not occur during daytime except the continuous FAI echo which appears at low-altitudes of the E-region $(90-100 \mathrm{~km})$ mostly around sunrise [1]. On the other hand, the present observations 

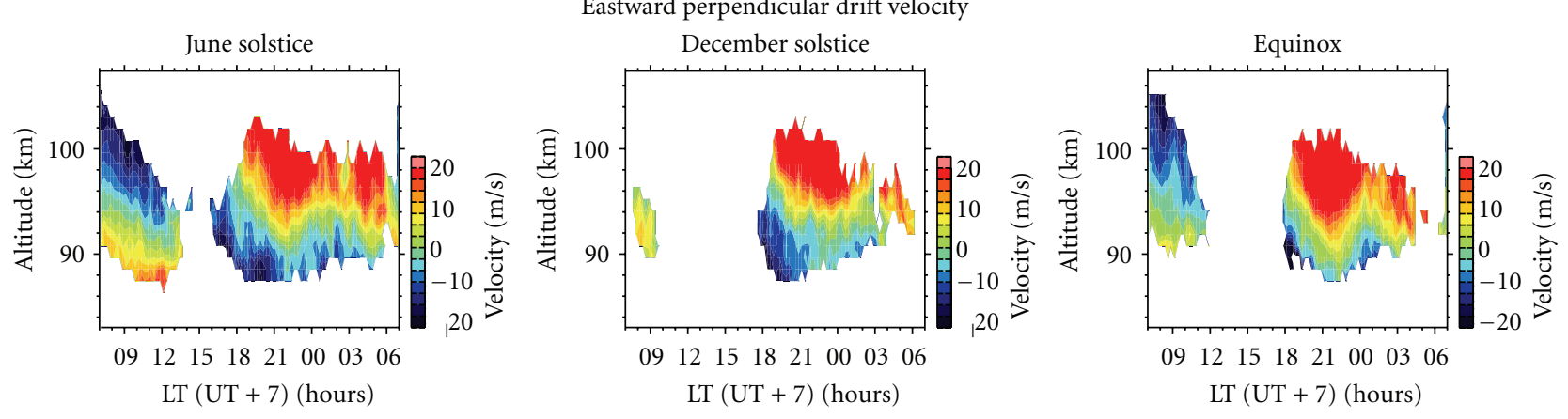

FIgURE 5: Same as Figure 4 but for the Doppler velocity toward the east.

show that the E-region FAIs over Kototabang, located at geomagnetically low-latitudes, occur even after sunrise until noon. The daytime $E$-region FAIs are frequently observed by the Gandanki MST radar in India, but they do not occur at Piura in Peru $[9,25]$. These results suggest that the occurrence of the daytime $E$-region FAIs at low-latitudes have a longitudinal dependence. Occurrence rate of the nighttime E-region FAIs at mid-latitudes shows a distinct seasonal variation with a maximum in summer $[2,26]$. This seasonal variation is consistent with that of Es layer. This could be because high plasma density and its gradient in the $E s$ layer are needed for generating the FAIs. The nighttime $E$ region FAI over Kototabang shows highest occurrence rate around June solstice, but its seasonal variation is not so distinct compared to that at mid-latitudes. This feature is similar to that of the nighttime E-region FAIs at Gadanki in India and Piura in Peru. Chau et al. [9] have shown that the nighttime FAIs over Piura occur frequently in summer. Phanikumar et al. [25] have shown that the FAI occurrence rate at Gadanki is high in both summer and winter and relatively less in equinoxes and pointed out that the FAI occurrence is consistent with inhomogeneity of the plasma density in the Es layer. The FAI occurrence rate at Kototabang also needs to be compared with the occurrence rate of the Es layer to reveal the mechanisms generating the $E$-region FAIs.

\section{Acknowledgments}

This work was supported by Grants-in-Aid for Scientific Research (20684021) and Strategic Funds for the Promotion of Science and Technology of the Ministry of Education, Culture, Sports, Science and Technology of Japan. The 30.8$\mathrm{MHz}$ radar is operated by STEL, Nagoya University, in collaboration with LAPAN and RISH, Kyoto University.

\section{References}

[1] M. Yamamoto, S. Fukao, R. F. Woodman, T. Ogawa, T. Tsuda, and S. Kato, "Midlatitude E region field aligned irregularities observed with the MU radar," Journal of Geophysical Research, vol. 96, no. A9, pp. 15943-15949, 1991.

[2] M. Yamamoto, S. Fukao, T. Ogawa, T. Tsuda, and S. Kato, "A morphological study on mid-latitude E-region fieldaligned irregularities observed with the MU radar," Journal of
Atmospheric and Terrestrial Physics, vol. 54, no. 6, pp. 769-777, 1992.

[3] S. Fukao, M. Yamamoto, R. T. Tsunoda, H. Hayakawa, and T. Mukai, "The SEEK (Sporadic-E Experiment over Kyushu) Campaign," Geophysical Research Letters, vol. 25, no. 10, pp. 1761-1764, 1998.

[4] R. F. Woodman, M. Yamamoto, and S. Fukao, "Gravity wave modulation of gradient drift instabilities in midlatitude sporadic E irregularities," Geophysical Research Letters, vol. 18, no. 7, pp. 1197-1200, 1991.

[5] R. T. Tsunoda, S. Fukao, and M. Yamamoto, "On the origin of quasi-periodic radar backscatter from midlatitude sporadic E," Radio Science, vol. 29, no. 1, pp. 349-365, 1994.

[6] R. B. Cosgrove and R. T. Tsunoda, "A direction-dependent instability of sporadic-E layers in the nighttime midlatitude ionosphere," Geophysical Research Letters, vol. 29, no. 18, 2002.

[7] T. Yokoyama, M. Yamamoto, and S. Fukao, "Computer simulation of polarization electric fields as a source of midlatitude field-aligned irregularities," Journal of Geophysical Research A, vol. 108, no. 2, article no. 1054, 2003.

[8] T. Ogawa, M. Yamamoto, and S. Fukao, "Middle and upper atmosphere radar observations of turbulence and movement of midlatitude sporadic E irregularities," Journal of Geophysical Research, vol. 100, no. A7, pp. 12173-12188, 1995.

[9] J. L. Chau, R. F. Woodman, and L. A. Flores, "Statistical characteristics of low-latitude ionospheric field-aligned irregularities obtained with the Piura VHF radar," Annales Geophysicae, vol. 20, no. 8, pp. 1203-1212, 2002.

[10] A. K. Patra, S. Sripathi, V. Sivakumar, and P. B. Rao, "Statistical characteristics of VHF radar observations of low latitude Eregion field-aligned irregularities over Gadanki," Journal of Atmospheric and Solar-Terrestrial Physics, vol. 66, no. 17, pp. 1615-1626, 2004.

[11] A. K. Patra, S. Sripathi, V. Sivakumar, and P. B. Rao, "Evidence of kilometre-scale waves in the lower E region from high resolution VHF radar observations over Gadanki," Geophysical Research Letters, vol. 29, no. 10, article 1499, 2002.

[12] C. J. Pan and P. B. Rao, "Low altitude quasi-periodic radar echoes observed by the Gadanki VHF radar," Geophysical Research Letters, vol. 29, no. 11, article 1530, 2002.

[13] S. Fukao, H. Hashiguchi, M. Yamamoto et al., "Equatorial atmosphere radar (EAR): system description and first results," Radio Science, vol. 38, no. 3, article 1053, 2003.

[14] A. K. Patra, T. Yokoyama, M. Yamamoto, T. Nakamura, T. Tsuda, and S. Fukao, "Lower E region field-aligned irregularities studied using the Equatorial Atmosphere radar and 
meteor radar in Indonesia," Journal of Geophysical Research A, vol. 112, no. 1, Article ID A01301, 2007.

[15] T. Tanaka and S. V. Venkateswaran, "Characteristics of fieldaligned E-region irregularities over Iioka $\left(36^{\circ} \mathrm{N}\right)$, Japan-II," Journal of Atmospheric and Terrestrial Physics, vol. 44, no. 5, pp. 395-406, 1982.

[16] A. K. Patra, "On the interpretation of the VHF radar echoes from the equatorial lower E region," Geophysical Research Letters, vol. 29, no. 14, article 1695, 2002.

[17] B. G. Fejer, E. R. dePaula, S. A. Gonzalez, and F. Woodman, "Average vertical and zonal F region plasma drifts over Jicamarca," Journal of Geophysical Research, vol. 96, no. A8, pp. 13901-13906, 1991.

[18] Y. Otsuka, F. Onoma, K. Shiokawa, T. Ogawa, M. Yamamoto, and S. Fukao, "Simultaneous observations of nighttime medium-scale traveling ionospheric disturbances and e region field-aligned irregularities at midlatitude," Journal of Geophysical Research A, vol. 112, no. 6, Article ID A06317, 2007.

[19] Y. Otsuka, K. Shiokawa, T. Ogawa, T. Yokoyama, and M. Yamamoto, "Spatial relationship of nighttime medium-scale traveling ionospheric disturbances and F region field-aligned irregularities observed with two spaced all-sky airglow imagers and the middle and upper atmosphere radar," Journal of Geophysical Research A, vol. 114, no. 5, Article ID A05302, 2009.

[20] K. Shiokawa, Y. Otsuka, and T. Ogawa, "Quasi-periodic southward-moving waves in 630-nm airglow images in the equatorial thermosphere," Journal of Geophysical Research, vol. 111, article A06301, 2006.

[21] M. F. Larsen, "A shear instability seeding mechanism for quasiperiodic radar echoes," Journal of Geophysical Research A, vol. 105, no. 11, Article ID 1999JA000290, pp. 24931-24940, 2000.

[22] S. Sripathi, A. K. Patra, V. Sivakumar, and P. B. Rao, "Shear instability as a source of the daytime quasi-periodic radar echoes observed by the Gadanki VHF radar," Geophysical Research Letters, vol. 30, no. 22, article 2149, 2003.

[23] N. Christakis, C. Haldoupis, Q. Zhou, and C. Meek, "Seasonal variability and descent of mid-latitude sporadic E layers at Arecibo," Annales Geophysicae, vol. 27, no. 3, pp. 923-931, 2009.

[24] J. D. Whitehead, "The formation of the sporadic-E layer in the temperate zones," Journal of Atmospheric and Terrestrial Physics, vol. 20, no. 1, pp. 49-58, 1961.

[25] D. V. Phanikumar, A. K. Patra, C. V. Devasia, and G. Yellaiah, "Seasonal variation of low-latitude E-region plasma irregularities studied using Gadanki radar and ionosonde," Annales Geophysicae, vol. 26, no. 7, pp. 1865-1876, 2008.

[26] C. Haldoupis and K. Schlegel, "Characteristics of midlatitude coherent backscatter from the ionospheric E region obtained with Sporadic E Scatter experiment," Journal of Geophysical Research, vol. 101, no. A6, pp. 13387-13397, 1996. 

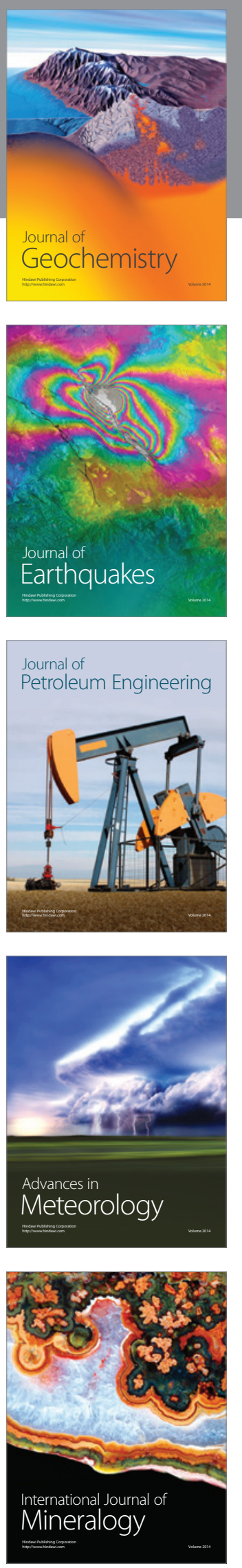
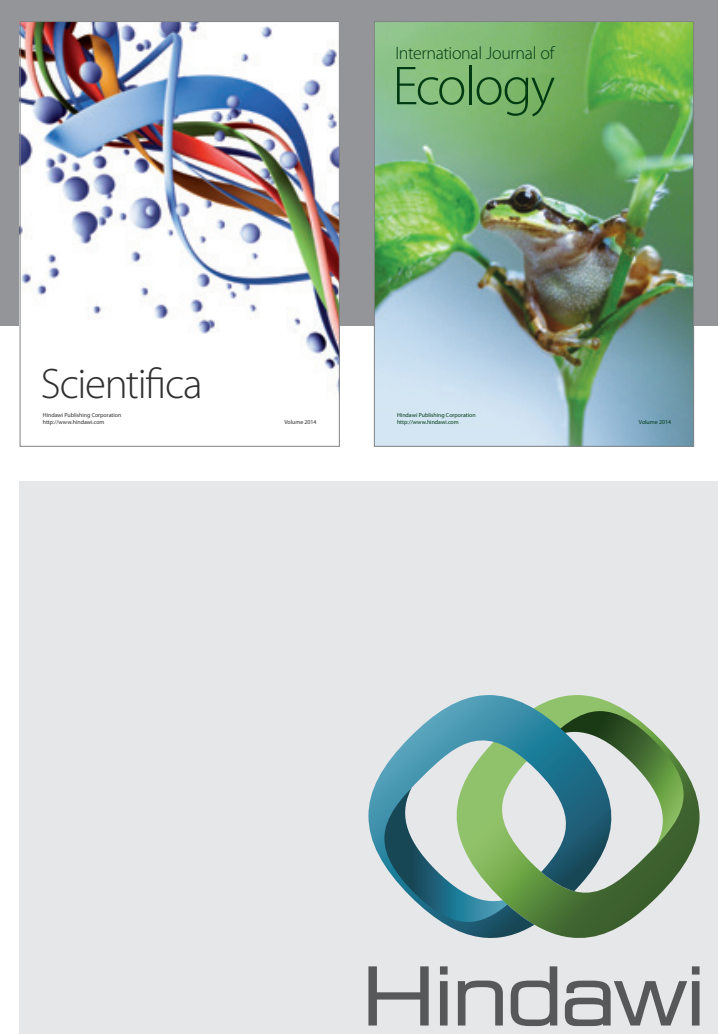

Submit your manuscripts at http://www.hindawi.com
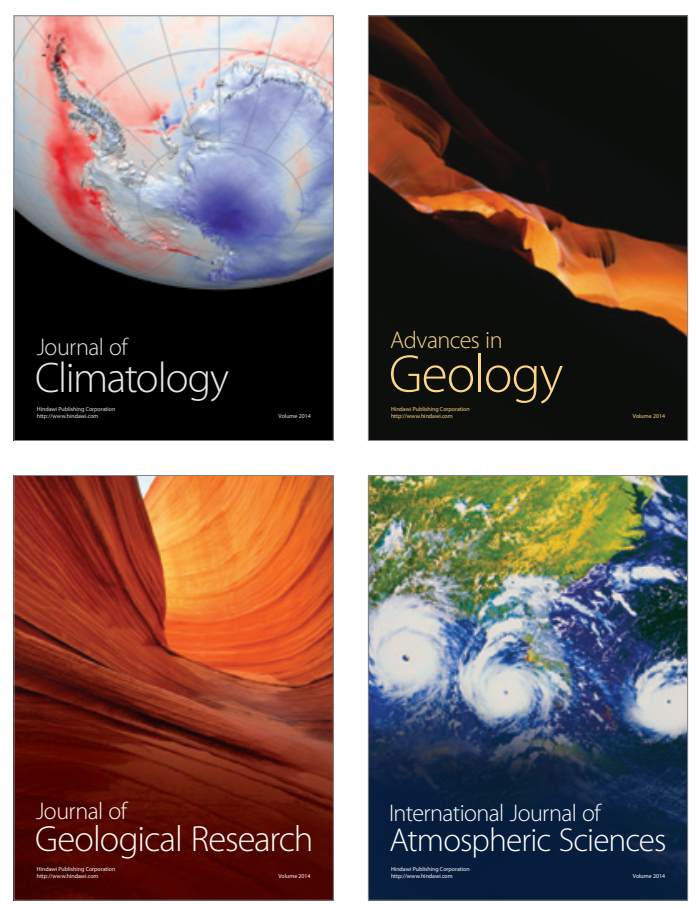
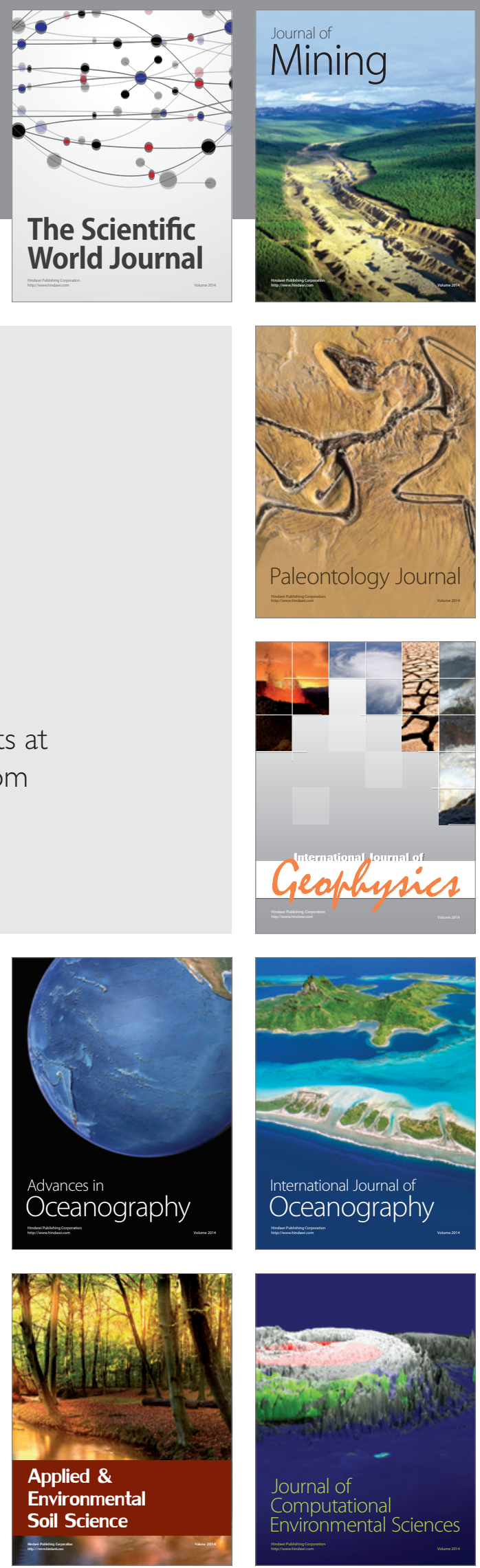